\title{
Diurnal changes of the intraocular pressure of patients with angle-closure glaucoma
}

\author{
A. SHAPIRO AND H. ZAUBERMAN \\ From the Department of Ophthalmology, Hadassah University Hospital, Jerusalem, Israel
}

SUMmaRY The diurnal curves of 21 patients (40 eyes) with angle-closure glaucoma and of 21 normotensive subjects (42 eyes) were studied. The patients with angle-closure glaucoma had a Vshaped diurnal curve that was completely different from the diurnal curve of the normotensive subjects. Most of the eyes of the patients with angle-closure glaucoma had a diurnal change of the intraocular pressure of $8 \mathrm{mmHg}$ or more, while in the normotensive subjects only 1 eye had a diurnal change as large as $8 \mathrm{mmHg}$.

The average normal intraocular pressure (IOP) of healthy eyes has been extensively studied. Measurements taken with the Schiotz tonometer yielded an average IOP of $15.5 \mathrm{mmHg}$ (Leydhecker et al., 1958) to $17.0 \mathrm{mmHg}$ (Weekers et al., 1955) and with a Goldmann applanation an average of $14.5 \mathrm{mmHg}$ (Draeger, 1959) to $15.6 \mathrm{mmHg}$ (Levene, 1961). In the normal eye the IOP shows diurnal variations. The amplitude of the diurnal variations has been found to be 3 to $7 \mathrm{mmHg}$ (Dobree, 1953; Alimuddin, 1956; Ericson, 1958; Katavisto, 1964; DukeElder and Jay, 1969), but in less than $1 \%$ of cases it was found to be as large as $10 \mathrm{mmHg}$ (Drance, 1960 ). In about $40 \%$ of normal persons the IOP is somewhat higher in the early morning, while in about $60 \%$ it may reach its peak at random times during the day (Alimuddin, 1956; Drance, 1960; Katavisto, 1964; Daubs, 1973).

There is no available study of the diurnal curve of patients known or suspected to be suffering from angle-closure glaucoma (ACG). The present study deals with the diurnal curve of 21 patients ( 40 eyes) suffering from ACG and the diurnal curve of 11 (20 eyes) of these 21 patients 3 months after peripheral iridectomy.

\section{Patients and methods}

Twenty-one patients (40 eyes) aged between 38 and 65 years were referred to Hadassah University Hospital Eye Department with the diagnosis of angle-closure glaucoma. Subjective complaints were ocular pain in 16 patients, blurred vision in 7 patients, light haloes in 4 patients. The diagnosis of

Address for reprints : Dr A. Shapiro, Department of Ophthalmology, Hadassah University Hospital, Jerusalem, Israel
ACG was confirmed by the presence of some or all of the following findings: narrow angle gonioscopically during a normotensive period, a positive dark room test, and the closure of the angle while the IOP was raised.

Each patient was admitted to hospital and his IOP was measured 7 times a day at 3-hour intervals between $0600 \mathrm{~h}$ and midnight with the Goldmann applanation tonometer. The pressure measurements were carried out during 2 successive days.

After the diagnosis of ACG was confirmed a peripheral iridectomy operation was recommended to all patients, but only 11 ( 20 eyes) out of 21 patients agreed to be operated upon. Three months after the operation these 11 patients underwent repeated diurnal curve examinations as described above.

A control group of 21 normotensive persons (42. eyes) with normal looking angles, aged between 39 and 65 years, underwent the same diurnal curve examinations. They were admitted to hospital in the Eye Department because of ptosis (4 cases), dacryostenosis (11 cases), and immature cataract (6 patients). None of the patients or members of the normotensive control group, had either anterior or posterior synechiae or any other ocular lesions that would to our knowledge have a definite influence on the IOP.

All topical and systemic medications were stopped at least 48 hours before the examinations. IOP measurements were evaluated by the Mann-Whitney $\mathrm{U}$ test when appropriate.

\section{Results}

The mean and standard deviation of the IOP during each of the time points in the diurnal curve of the 
Table 1 Mean and standard deviation of IOP in $\mathrm{mmHg}$ of the patients with ACG, the patients who had peripheral iridectomy, and the normotensive control group

\begin{tabular}{|c|c|c|c|c|c|c|c|c|c|}
\hline & & & \multicolumn{7}{|c|}{ Hours of measurement of $I O P$} \\
\hline & & & $0600 h$ & $0900 h$ & $1200 \mathrm{~h}$ & $1500 h$ & $1800 \mathrm{~h}$ & $2100 \mathrm{~h}$ & $2400 h$ \\
\hline \multirow{2}{*}{\multicolumn{2}{|c|}{ Patients with ACG }} & Mean & $18 \cdot 56$ & $18 \cdot 22$ & $17 \cdot 39$ & $16 \cdot 87$ & $17 \cdot 27$ & $17 \cdot 71$ & $18 \cdot 77$ \\
\hline & & SD & $7 \cdot 00$ & $7 \cdot 87$ & $7 \cdot 74$ & $5 \cdot 55$ & $7 \cdot 29$ & $10 \cdot 41$ & 10.91 \\
\hline \multirow{4}{*}{$\begin{array}{l}\text { Patients who had } \\
\text { peripheral iridectomy } \\
\text { procedure }\end{array}$} & \multirow{2}{*}{$\begin{array}{l}\text { Before } \\
\text { the } \\
\text { operation }\end{array}$} & Mean & $17 \cdot 46$ & 17.89 & $16 \cdot 27$ & $17 \cdot 05$ & $18 \cdot 03$ & $18 \cdot 43$ & $19 \cdot 05$ \\
\hline & & SD & $4 \cdot 85$ & $6 \cdot 54$ & $4 \cdot 19$ & $5 \cdot 31$ & $7 \cdot 42$ & $11 \cdot 66$ & 12.94 \\
\hline & \multirow{2}{*}{$\begin{array}{l}\text { After } \\
\text { the } \\
\text { operation }\end{array}$} & Mean & $15 \cdot 58$ & $14 \cdot 11$ & 14.03 & 13.95 & $14 \cdot 50$ & $14 \cdot 08$ & $14 \cdot 53$ \\
\hline & & SD & $4 \cdot 23$ & $4 \cdot 14$ & $3 \cdot 11$ & $2 \cdot 77$ & $3 \cdot 78$ & $3 \cdot 28$ & $3 \cdot 36$ \\
\hline \multirow{2}{*}{\multicolumn{2}{|c|}{ Normotensive control group }} & Mean & 14.44 & $14 \cdot 21$ & $13 \cdot 64$ & $14 \cdot 31$ & 13.95 & $13 \cdot 51$ & $13 \cdot 57$ \\
\hline & & SD & 3.22 & $2 \cdot 35$ & $3 \cdot 10$ & $3 \cdot 13$ & 3.01 & 2.88 & 3.07 \\
\hline
\end{tabular}

patients with ACG, the patients who underwent peripheral iridectomy, and the normotensive control group are given in Table 1 and Fig 1 . It is seen that the patients with ACG had a higher IOP average than the normotensive control group. The highest IOP in the patients with ACG was at midnight, and at $0600 \mathrm{~h}$ the IOP was only slightly lower than that at midnight. The lowest IOP was at $1500 \mathrm{~h}$. The curve had a V-shape with a statistically significant difference between the pressures at $0600 \mathrm{~h}$ and midnight and the pressure at $1500 \mathrm{~h}(\mathrm{P}<0.01)$. In the normotensive control group the highest IOP was at $0600 \mathrm{~h}$ with a statistically insignificant change during the day $(P>0.05)$. A statistical analysis

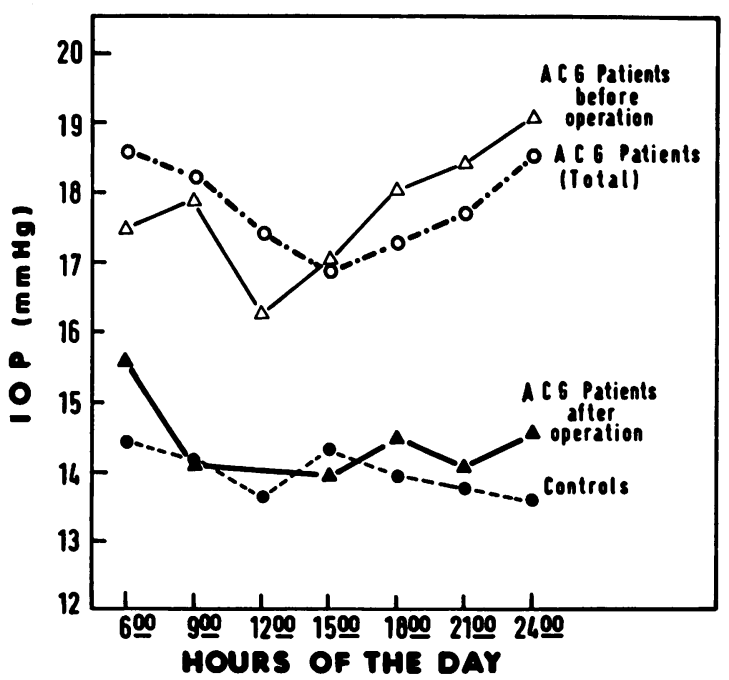

Fig. 1 Diurnal curve of IOP of the patients with $A C G$, the patients with ACG who had peripheral iridectomy before and after the operation, and the normotensive control group proved that the diurnal curve of the patients with ACG was completely different from the diurnal curve of the normotensive control group $(P<0 \cdot 01)$. The patients who underwent a peripheral iridectomy showed a diurnal curve that was statistically similar to that of the normotensive control group $(P<0.05)$.

The diurnal changes in the patients with ACG, the patients after undergoing peripheral iridectomy, and the normotensive control group are given in Fig. 2. A diurnal change of $8 \mathrm{mmHg}$ was noted in the control group in 1 eye, and only in 1 of the 2 diurnal curve examinations performed on that eye. In the patients with ACG a diurnal change of $8 \mathrm{mmHg}$ or more, at least in 1 of the 2 diurnal curve examinations, was noted in $26(65 \%)$ eyes. In the patients who underwent peripheral iridectomy the diurnal changes in IOP were not as great as before the operation, but still 8 eyes $(40 \%)$ had in 1 of the 2 diurnal curve examinations a change of $8 \mathrm{mmHg}$ or more. The largest diurnal variation in the patients with peripheral iridectomy was 12 mmHg.

In each of the diurnal curve examinations the lowest IOP measurements of the patients with ACG ranged between 7 and $25 \mathrm{mmHg}$, with mean of $13.7 \mathrm{mmHg}$ and a median of $20.0 \mathrm{mmHg}$. The lowest IOP measurements of the normotensive control group ranged between 7 and $16 \mathrm{mmHg}$, with a mean of $11.5 \mathrm{mmHg}$ and a median of 12.0 mmHg.

\section{Discussion}

The present study includes a comparison of the diurnal curve and the diurnal change of patients with ACG and a normotensive control group. The difference between the diurnal curves is highly significant $(P<0.01)$. In the patients with ACG the 


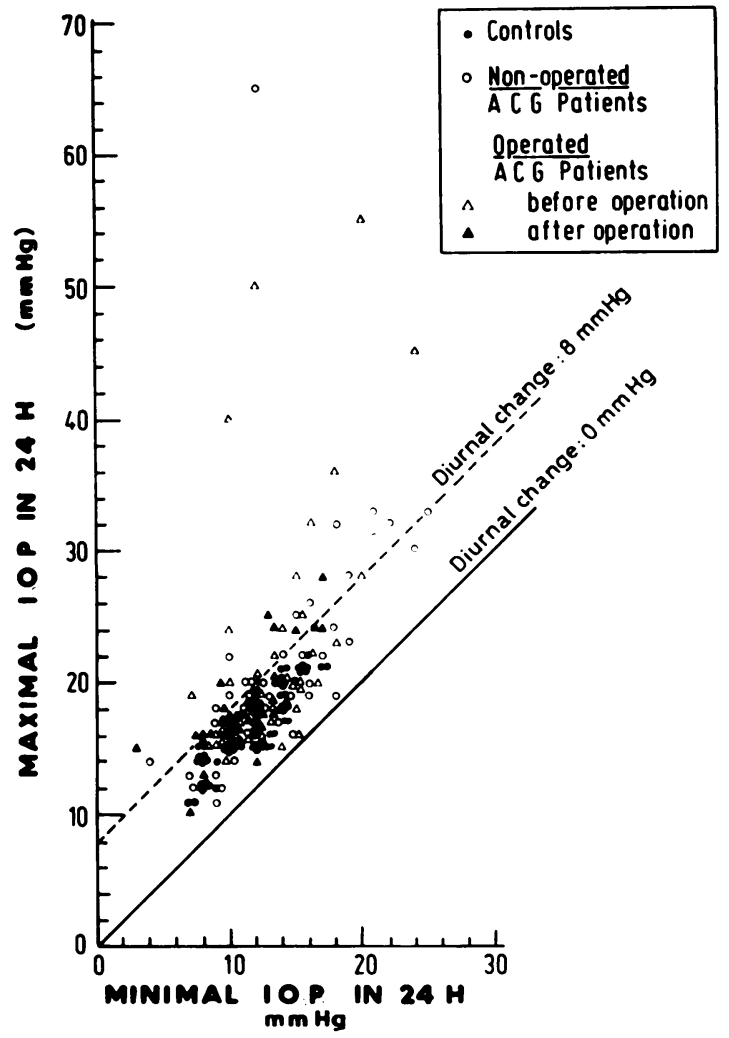

Fig. 2 Maximal and minimal diurnal IOP of the patients with ACG who were not operated on, the patients with ACG who had peripheral iridectomy before and after the operation, and the normotensive control group

average IOP is higher than that of the normotensive control group at any time point in the diurnal curve. In the patients with ACG high tensions are at $0600 \mathrm{~h}$ and midnight, and a comparatively low tension is at $1500 \mathrm{~h}$, giving to the diurnal curve a V-shape. The diurnal curve in the normotensive control group has no significant fluctuations. Dilatation of the pupil in darkness with subsequent disturbance to the aqueous drainage can explain the V-shape of ACG patients' diurnal curve. Patients after peripheral iridectomy have a diurnal curve that is more like that of the control group, and that is due to the abolition of the possibility of a pupillary block.

In other studies (Dobree, 1953; Alimuddin, 1956; Ericson, 1958; Katavisto, 1964), as well as in our control group, the IOP variations of the normal people rarely exceeded $8 \mathrm{mmHg}$. Therefore we adopted Drance's definition that a diurnal variation of $8 \mathrm{mmHg}$ or more is abnormal (Drance, 1960). A change of $8 \mathrm{mmHg}$ or more was noted at least in 1 of the 2 days' diurnal curves in $65 \%$ of the eyes of the patients with ACG, while in the normotensive control group there was a change of $8 \mathrm{mmHg}$ in $2 \%$ of the eyes, and the rest had a lower diurnal change. We have no explanation of the finding that in $40 \%$ of the eyes of the patients after peripheral iridectomy there was still a change of 8 to $12 \mathrm{mmHg}$, at least in 1 of the 2 days' diurnal curves. That change was in spite of the fact that none of the patients had plateau iris.

It is worth noting that most of the patients with ACG have IOP measurements during some hours of the day which are almost as low as those of the normotensive control group. These patients are usually given a provocative test to detect increase of IOP. It seems to us that provocative tests are influenced by the pressure at the beginning of the test and by the trend of the diurnal curve. A patient suspected of having ACG may on one occasion have a positive result and on another a negative result merely because the examinations are started at 2 different points of the diurnal IOP curve. We intend to investigate that carefully.

The present study shows that a diurnal curve with a V-shape and a difference of $8 \mathrm{mmHg}$ or more during 24 hours can be a valuable test confirming the diagnosis of ACG. Its results are not subject to artifacts as those of the provocative tests may be.

\section{References}

Alimuddin, M. (1956). Normal intraocular pressure. British Journal of Ophthalmology, 40, 366-372.

Daubs, J. G. (1973). Patterns of diurnal variation in the intraocular pressure of airline pilots. Aerospace Medicine, 44, 914-917.

Dobree, J. H. (1953). Vascular changes that occur during the phasic variation of tension in chronic glaucoma. British Journal of Ophthalmology, 37, 293-300.

Draeger, J. (1959). Untersuchungen uber den Rigiditätskoeffizienten. Documenta Ophthalmologica, 13, 431-486.

Drance, S. M. (1960). The significance of the diurnal phasic variation of intraocular pressure in normal and glaucomatous eyes. Archives of Ophthalmology, 64, 494-501.

Duke-Elder, S., and Jay, B. (1969). Diseases of the lens and vitreous; glaucoma and hypotony. In System of Ophthalmology, Vol. XI, p. 456. Kimpton: London.

Ericson, L. (1958). Twenty-four hourly variations of aqueous flow. Acta Ophthalmologica, Supplementum 50.

Katavisto, M. (1964). The diurnal variations of ocular tension in glaucoma. Acta Ophthalmologica, Supplementum 78.

Levene, R. Z. (1961). Tonometry and tonography in a group health population. Archives of Ophthalmology, 66, 42-47.

Leydhecker, W., Akiyama, K., and Neumann, H. G. (1958). Der intraokulare Druck gesunder menschlicher Augen. Klinische Monatsblätter für Augenheilkunde, 133, 662-670.

Weekers, R., Prijot, E., and Delmarcelle, Y. (1955). Indications, resultant de leur mode d'action, des divers traitements médicaux et chirurgicaux de l'hypertension oculaire. Documenta Ophthalmologica, 9, 314-337. 